\title{
Involvement of $\mathrm{BH} 4$ domain of bcl-2 in the regulation of HIF-1-mediated VEGF expression in hypoxic tumor cells
}

\author{
D Trisciuoglio ${ }^{1}$, C Gabellini ${ }^{1,2}$, M Desideri ${ }^{1}$, Y Ragazzoni ${ }^{1}$, T De Luca ${ }^{1}$, E Ziparo ${ }^{2}$ and D Del Bufalo*,1
}

In addition to act as an antiapoptotic protein, B-cell lymphoma (bcl)-2 can also promote tumor angiogenesis. In this context, we have previously demonstrated that under hypoxia bcl-2 promotes hypoxia-inducible factor-1 (HIF-1)-mediated vascular endothelial growth factor (VEGF) expression in melanoma and breast carcinoma. Here, we report on the role of the BH4 domain in bcl-2 functions, by showing that removal of or mutations at the BH4 domain abrogate the ability of bcl-2 to induce VEGF protein expression and transcriptional activity under hypoxia in human melanoma cells. We have also extended this observation to other human tumor histotypes, such as colon, ovarian and lung carcinomas. The involvement of BH4 on HIF-1 $\alpha$ protein expression, stability, ubiquitination and HIF-1 transcriptional activity was also demonstrated in melanoma experimental model. Moreover, we validated the role of the BH4 domain of bcl-2 in the regulation of HIF-1/VEGF axis, demonstrating that BH4 peptide is sufficient to increase HIF- $1 \alpha$ protein half-life impairing HIF-1 $\alpha$ protein ubiquitination, and to enhance VEGF secretion in melanoma cells exposed to hypoxia. Finally, we found that the mechanism by which bcl-2 regulates HIF-1-mediated VEGF expression does not require $\mathrm{BH} 1$ and $\mathrm{BH} 2$ domains, and it is independent of antiapoptotic and prosurvival function of bcl-2.

Cell Death and Differentiation (2011) 18, 1024-1035; doi:10.1038/cdd.2010.175; published online 14 January 2011

B-cell lymphoma (bcl)-2 family proteins are defined by the sequence homology shared within four conserved bcl-2 homology $(\mathrm{BH})$ domains, $\mathrm{BH} 1, \mathrm{BH} 2, \mathrm{BH} 3$ and $\mathrm{BH} 4{ }^{1}$ Whereas the $\mathrm{BH} 1$ and $\mathrm{BH} 2$ domains of bcl-2 are required for dimerization with proapoptotic proteins, the $\mathrm{BH} 3$ domain is crucial for homo- and hetero-dimerization between the bcl-2 family members. The amino-terminal $\mathrm{BH} 4$ domain is mainly found in the bcl-2 family members with death-repressing activity, ${ }^{1}$ but it is also present in some proapoptotic molecules. $^{2} \mathrm{BH} 4$ domain of bcl-2 and bcl-xL is critical for interaction with and/or regulation of several proteins involved in apoptosis ${ }^{3-6}$ and all $\mathrm{BH}$ domains are necessary for the antiapoptotic function of bcl-2 and bcl-xL. ${ }^{7}$ In addition to protecting from apoptosis and increasing survival, bcl-2 and $\mathrm{bcl}-\mathrm{xL}$ are involved in several other important functions, including angiogenesis. ${ }^{8-16}$ In this context, we have previously reported that bcl-2 expression in tumor cells exposed to hypoxia increases the expression of vascular endothelial growth factor (VEGF) through the hypoxia-inducible factor-1 (HIF-1) ${ }^{9,11}$ In vitro and in vivo inhibition of bcl-2 functions has a strong effect on HIF-1 target genes that, in some cases, is functionally unrelated to the prosurvival effect of bcl-2. ${ }^{17-19}$ These results, together with data demonstrating the ability of bcl-2 to orchestrate a contact-independent crosstalk between endothelial and tumor cells promoting tumor growth, ${ }^{20}$ identify a new function for bcl-2 and bcl-xL that goes beyond their role in cell survival. An important point, yet to be studied in depth, is which domain(s) of bcl-2 account for the regulation of angiogenesis by bcl-2 through a VEGF-mediated HIF-1dependent pathway. We recently demonstrated that bcl-2 induces HIF- $1 \alpha$ protein stabilization through the impairment of ubiquitin-dependent HIF-1 $\alpha$ degradation involving the molecular chaperone heat shock protein 90 (HSP90). ${ }^{21}$ In this work, we investigated the possible role of the $\mathrm{BH}$ domains of bcl-2 in the ability of this protein to regulate HIF-1mediated VEGF expression in cooperation with hypoxia. This study shows that bcl-2 is implicated in HIF- $1 \alpha$ stabilization in hypoxic conditions, through a mechanism that involves the $\mathrm{BH} 4$ domain, but not the $\mathrm{BH} 1$ or $\mathrm{BH} 2$.

\section{Results}

The BH4 domain, but not the $\mathrm{BH} 1$ or $\mathrm{BH} 2$, is necessary for VEGF induction by wild-type bcl-2 under hypoxia. To address the relevance of the different domains of bcl-2 in its ability to increase VEGF expression under hypoxia, M14 human melanoma cells were transiently transfected with expression vectors encoding human wild-type (wt) bcl-2, or different point-mutated or deleted forms of this protein (Figures $1 \mathrm{a}$ and b). As shown by enzyme-linked

\footnotetext{
${ }^{1}$ Experimental Chemotherapy Laboratory, Experimental Oncology Department, Regina Elena Cancer Institute, Rome, Italy and ${ }^{2}$ Section of Histology and Medical Embryology, Department of Anatomy, Histology, Forensic medicine and orthopedics, Sapienza University, Rome, Italy

*Corresponding author: D Del Bufalo, Experimental Chemotherapy Laboratory, Regina Elena Cancer Institute, Via delle Messi d'Oro 156, 00158 Rome, Italy.

Tel: + 39065266 2575; Fax: + 39065266 2592; E-mail: delbufalo@ifo.it

Keywords: bcl-2; BH domain; HIF-1; VEGF; cancer

Abbreviations: Bcl-2, B-cell lymphoma 2; BH, Bcl-2 homology; PARP, poly(ADP-ribose) polymerase; HIF-1, hypoxia-inducible factor 1; VEGF, vascular endothelial growth factor; CPT, camptothecin; CHX, cyclohexamide; ROS, reactive oxygen species; HSP90, heat shock protein 90; ELISA, enzyme-linked immunosorbent assay; HRE, hypoxic responsive element

Received 04.6.10; revised 26.11.10; accepted 29.11.10; Edited by A Villunger; published online 14.1.11
} 
a

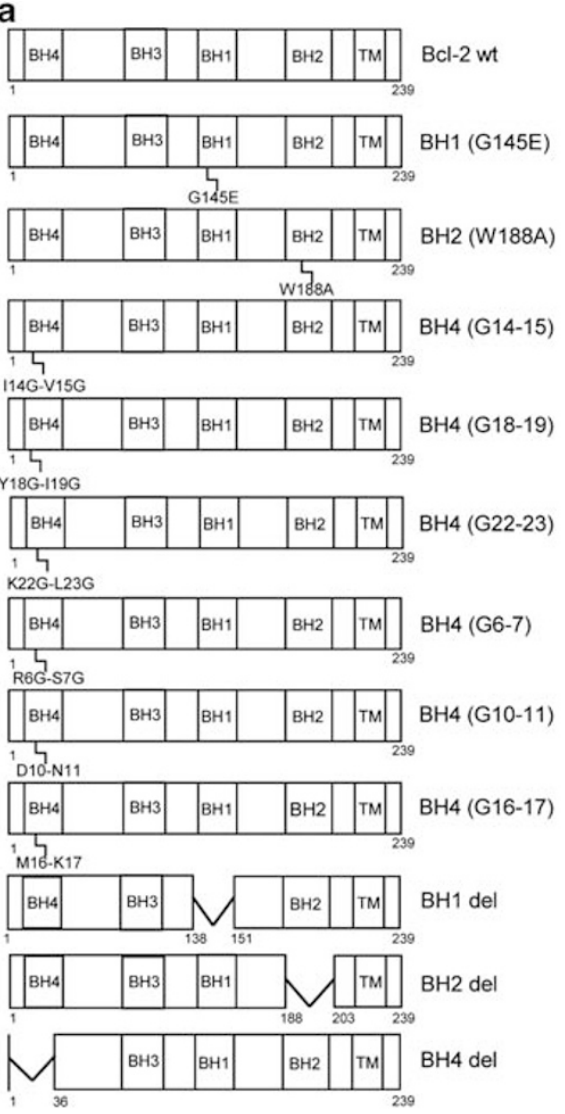

b

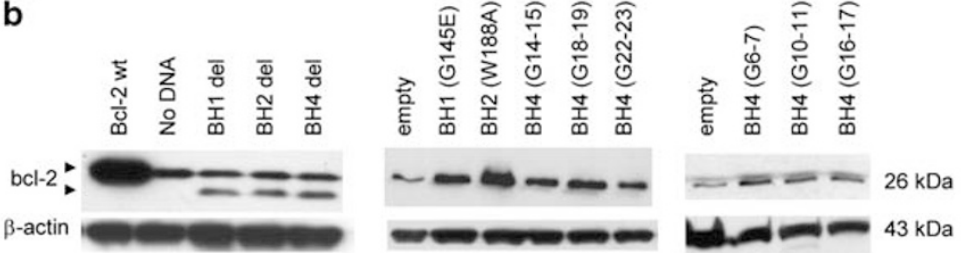

C

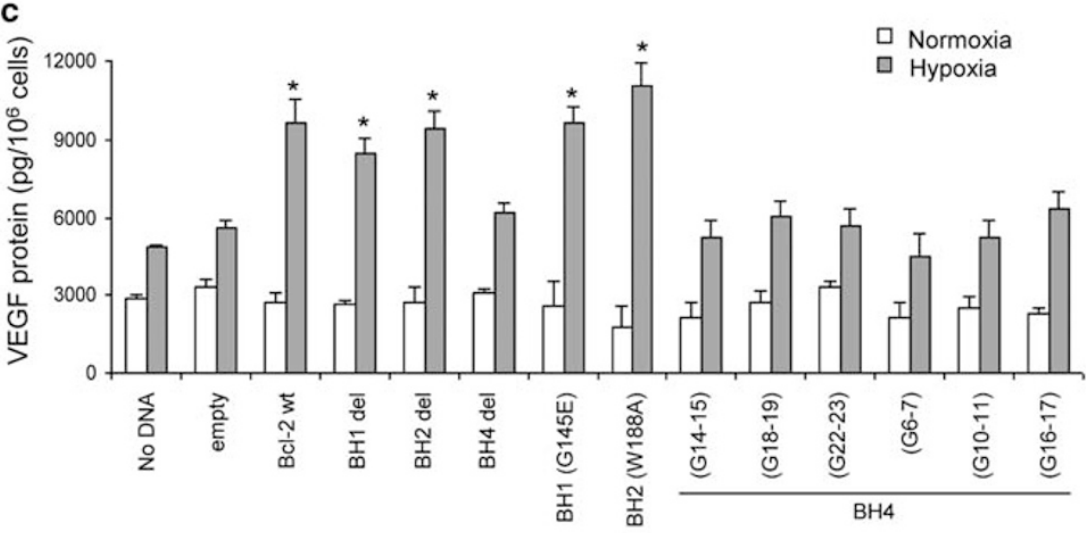

Figure 1 The $\mathrm{BH} 4$ domain, but not $\mathrm{BH} 1$ or $\mathrm{BH} 2$, is necessary for VEGF induction by wild-type (wt) bcl-2 under hypoxia. (a) A schematic representation and names of structural constructs encoding the human wt bcl-2 or different bcl-2 mutants that have been used throughout the paper: the bcl-2 point mutants at the BH1 domain (G145E, amino acid residue 145 from glycine to glutamic acid), at the BH2 domain (W188A, amino acid residue 188 from tryptophan to alanine), and six different dicodon bcl-2 mutants at the BH4 domain (G14-15, amino acid residues 14 (isoleucine) and 15 (valine) replaced by glycines; G18-19, amino acid residues 18 (tyrosine) and 19 (isoleucine) replaced by glycines; G22-23, amino acid residues 22 (lysine) and 23 (leucine) replaced by glycines; G6-7, amino acid residues 6 (arginine) and 7 (serine) replaced by glycines; G1011 , amino acid residues 10 (aspartic acid) and 11 (asparagine) replaced by glycines; G16-17, amino acid residues 16 (methionine) and 17 (lysine) replaced by glycines); the bcl-2 deleted mutants of $\mathrm{BH} 4$ (residues from 1 to 36 ), $\mathrm{BH} 1$ (residues from 138 to 151) or BH2 (residues from 188 to 203) regions. All the mutations of bcl-2 protein, excluding G6-7, G10-11 and G16-17, impair its antiapoptotic activity. (b) Western blot analysis of bcl-2 protein expression on M14 cells untransfected (no DNA) or transiently transfected with empty vector (empty) or with vectors encoding wt or mutated bcl-2 protein. Two bands, indicative of the higher endogenous full-length and shorter exogenous bcl-2 protein, were observed in cells overexpressing bcl-2 deleted of $\mathrm{BH} 1, \mathrm{BH} 2$ or $\mathrm{BH} 4$ regions, while a single high band was observed in control cells (untransfected or transfected with empty vector) and in cells overexpressing wt or point-mutated bcl-2 protein. Western blots representative of three independent experiments with similar results are shown. $\beta$-actin is shown as loading and transferring control. (c) VEGF protein expression evaluated by ELISA on M14 cells transiently transfected with vectors encoding wt or mutated bcl-2 exposed to normoxia or hypoxia. Results represent the average \pm S.D. of three independent experiments. $P$-values were calculated between control and $w t$ or mutated bcl-2-overexpressing cells $\left({ }^{*} P<0.01\right)$

immunosorbent assay (ELISA; Figure 1c), while under normoxia no differences were observed regardless bcl-2 status, under hypoxia the VEGF protein level increased in all cells compared with normoxia. In addition, under hypoxia higher levels of VEGF protein were observed in cells overexpressing bcl-2 wt or deleted in the $\mathrm{BH} 1$ or $\mathrm{BH} 2$ domains when compared with control cells, besides higher level of bcl-2 protein was reached in cells overexpressing the wt compared with mutated bcl-2 protein (Figure $1 \mathrm{~b}$ ), thus indicating that those low levels of $\mathrm{BH} 1 / \mathrm{BH} 2$ deleted proteins are sufficient to sustain HIF-1/VEGF pathway activation in hypoxia. On the contrary, the level of the VEGF protein was not increased in cells expressing bcl-2 deleted in the $\mathrm{BH} 4$ domain relative to control cells. As reported in Figure 1c, all dicodon mutations in the residues of $\mathrm{BH} 4$ domain abrogated the ability of the $w t$ form of bcl-2 to cooperate with hypoxia to induce VEGF expression. On the contrary, point mutations within the $\mathrm{BH} 1$ or $\mathrm{BH} 2$ domains did not affect bcl-2-induced VEGF protein secretion.

The role of the different mutations on bcl-2-induced VEGF expression (Figure 2b) and VEGF transcriptional activity (Figure 2c) was also evaluated, under normoxia or hypoxia, using stably transfected clones expressing $w t$ or mutated bcl-2 (Figure 2a). Under normoxia, there were not differences in VEGF protein secretion regardless bcl-2 status. By contrast, under hypoxia $w t$ bcl-2 overexpression significantly increased both the VEGF protein secretion (Figure 2b) and VEGF promoter activity (Figure 2c) when compared with control cells. However, the deletion of the $\mathrm{BH} 4$ domain abrogates the ability of bcl-2 to cooperate with hypoxia to induce VEGF expression and promoter activity: both parameters were similar in the control clone and in bcl-2 deleted of $\mathrm{BH} 4$ 

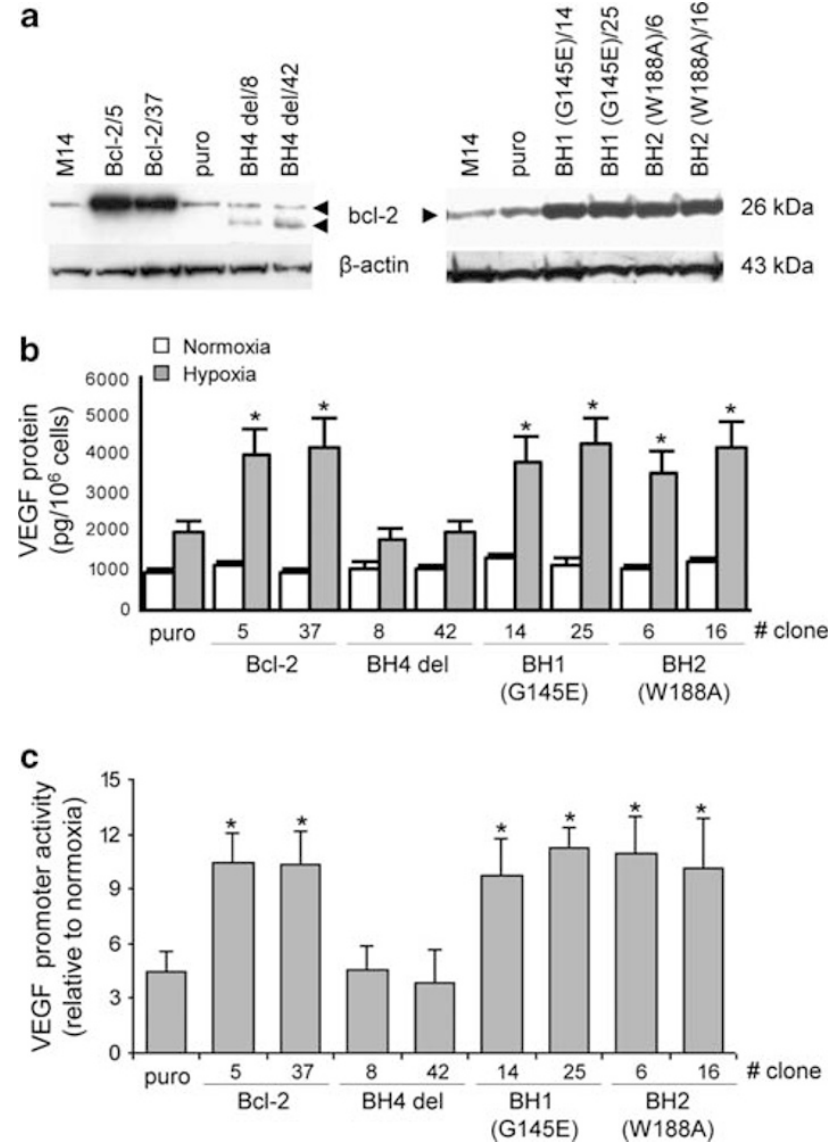

Figure 2 The $\mathrm{BH} 4$ domain, but not the $\mathrm{BH} 1$ or $\mathrm{BH} 2$, is necessary for VEGF induction by wild-type (wt) bcl-2 under hypoxia. Western blot analysis of bcl-2 protein expression (a), VEGF protein expression evaluated by ELISA (b) and VEGF promoter activity (c) in M14 cells, a control clone (puro), clones overexpressing wt bcl-2 (Bcl-2/5, Bcl-2/37), bcl-2 deleted of the $\mathrm{BH} 4$ domain (BH4 del/8, $\mathrm{BH} 4$ del/42), bcl-2 with point mutations at the $\mathrm{BH} 1(\mathrm{BH} 1$ (G145E)/14, $\mathrm{BH} 1$ (G145E)/25) or at the $\mathrm{BH} 2(\mathrm{BH} 2(\mathrm{~W} 188 \mathrm{~A}) / 6, \mathrm{BH} 2(\mathrm{~W} 188 \mathrm{~A}) / 16)$ domains. (a) Western blots representative of three independent experiments with similar results are shown. $\beta$-actin is shown as loading and transferring control. (c) The luciferase construct containing the VEGF 1511-bp proximal promoter sequence was transiently transfected into cells and then exposed to normoxia or hypoxia for $24 \mathrm{~h}$. Luciferase values were normalized for transfection efficiency (luciferase/ $\beta$ galactosidase activities ratios). The results are reported as fold induction relative to normoxia. (b and $\mathbf{c}$ ) Results represent the average \pm S.D. of three independent experiments. $P$-values were calculated from control and bcl-2 wt or mutated bcl-2-overexpressing cells $\left({ }^{*} P<0.01\right)$

transfectants (Figures $2 \mathrm{~b}$ and $\mathrm{c}$ ). On the contrary, point mutations at the $\mathrm{BH} 1$ or $\mathrm{BH} 2$ domains did not affect bcl-2induced VEGF protein secretion and promoter activity under hypoxia.

We also extended the BH4-dependent role of bcl-2 in the regulation of hypoxia-induced VEGF expression to other melanoma cells and other tumor histotypes (Figure 3). In normoxia, the levels of secreted VEGF protein were similar in all cells regardless bcl-2 status and expression. By contrast, the hypoxic induction of the VEGF protein was increased after forced expression of $w t$ bcl-2 in melanoma (PLF2, JR1) (Figure 3a) and colon (HT29), ovarian (CaOV3) and lung (H1299) carcinoma (Figure $3 b$ ) cells when compared with control cells, while no differences were observed after forced expression of the bcl-2 protein deleted of the $\mathrm{BH} 4$ domain.
The increase in HIF-1 $\alpha$ protein expression by bcl-2 is dependent on its $\mathrm{BH} 4$ domain. We investigated on the role of different bcl-2 mutations on the bcl-2-induced HIF-1 transcriptional activity and $\mathrm{HIF}-1$ proteins expression in melanoma cells, stably or transiently transfected with wt or different mutated bcl-2. Under hypoxia wt bcl-2 clones showed about twofold increase in the activity of the HIF-1dependent gene transcription when compared with the transfected control cells, whereas the clones overexpressing bcl-2 deleted of its $\mathrm{BH} 4$ domain showed HIF-1 transcriptional activity similar to that observed in the transfected control cells (Figure 4a). Transfectants expressing point mutants within the $\mathrm{BH} 1$ or $\mathrm{BH} 2$ domains of bcl-2 showed HIF-1 transcriptional activity similar to that of the clones overexpressing the wt bcl-2 protein (data not shown). As shown in Figure 4b, after exposure to hypoxia, the HIF-1 $\alpha$ protein expression was detectable in control cells, while it became more evident after forced expression of $w t$ bcl-2. Similar to control cells, both clones carrying bcl-2 deleted of the $\mathrm{BH} 4$ domain showed a low HIF-1 $\alpha$ protein expression. Under hypoxia, high levels of $\mathrm{HIF}-1 \alpha$ protein were also observed in the cells transiently transfected with $w t$ bcl- 2 when compared with the cells transiently transfected with both empty vector and vector encoding bcl-2 deleted of its $\mathrm{BH} 4$ domain. On the other hand, similar levels of the HIF-1 $\alpha$ protein were observed in cells transiently transfected with $w t$ bcl-2 and in those expressing bcl-2 point mutants within the $\mathrm{BH} 1$ or $\mathrm{BH} 2$ domains (Figure $4 \mathrm{c}$ ). Besides, cells expressing bcl-2 dicodon mutants in the $\mathrm{BH} 4$ domain showed levels of the HIF- $1 \alpha$ protein comparable to those showed by cells transiently transfected with the empty vector (Figure 4d), independently from their response to apoptosis. Moreover, under hypoxia HIF-1 $\beta$ expression was not modulated in any of the cell lysates regardless the bcl-2 status (Figures $4 b-d$ ). In normoxia, levels of HIF-1 $\alpha$ protein were undetectable in all cells regardless bcl-2 status and expression (data not shown).

The increase in HIF-1 $\alpha$ protein stability by bcl-2 is dependent on its BH4 domain. To gain further insight into the mechanisms of bcl-2-induced HIF-1 $\alpha$ protein expression, we examined the HIF-1 $\alpha$ mRNA levels in melanoma cells stably transfected with wt or mutated bcl-2. No difference in HIF-1 $\alpha$ mRNA levels were observed between cells exposed to normoxia or hypoxia regardless bcl-2 status, thus confirming that bcl-2 overexpression under hypoxia did not modulate HIF-1 $\alpha$ gene expression at transcriptional level ${ }^{9}$ and excluding the involvement of $\mathrm{BH} 4$ domain in the regulation of HIF- $1 \alpha$ mRNA levels (Figure 5a). Next, we examined the effects of ectopic expression of $w t$ bcl-2 or bcl-2 deleted in $\mathrm{BH} 4$ domain on $\mathrm{HIF}-1 \alpha$ protein at the posttranscriptional level using the proteasome inhibitor MG132 (Figure 5b). The accumulation of HIF-1 $\alpha$ protein after MG132 treatment was identical in all cells regardless bcl-2 status, indicating that neither wt nor mutated form of bcl-2 affect HIF-1 $\alpha$ protein synthesis (Figure $5 \mathrm{~b}$ ). To directly test whether bcl-2 status in hypoxic cells is associated with a modulation of HIF-1 $\alpha$ protein stability, we measured HIF- $1 \alpha$ protein half-life. As depicted in Figures $5 c$ and $d$, a time- 

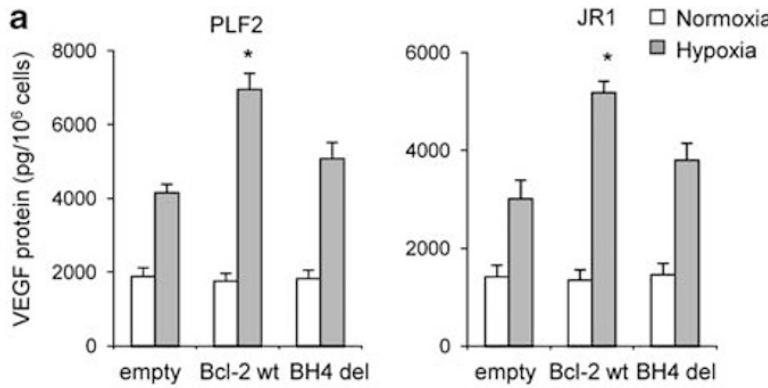

b
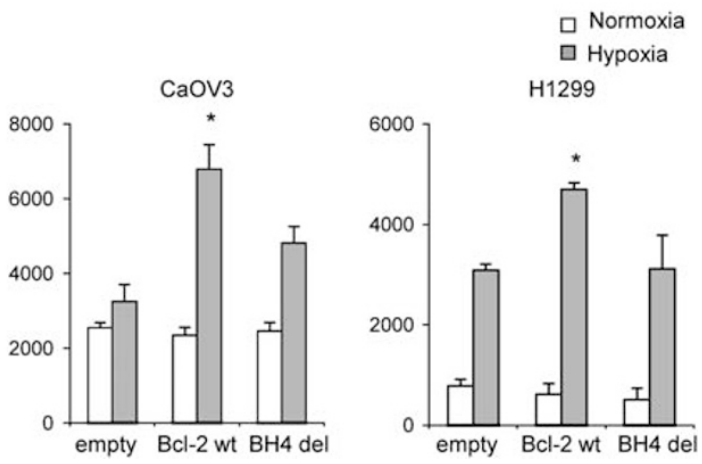

Figure 3 Forced expression of wild-type (wt) bcl-2, but not bcl-2 deleted of $\mathrm{BH} 4$ domain, increases hypoxia-induced VEGF protein expression in several tumor cell lines of different origin. (a and $\mathbf{b}$ ) VEGF protein expression evaluated by ELISA in human PLF2 and JR1 melanomas (a), HT29 colon, CaOV3 ovarian and H1299 lung carcinoma cells (b) transiently transfected with control vector (empty) or constructs encoding bcl-2 wt (Bcl-2 wt) or deleted of the BH4 domain (BH4 del) and exposed to normoxia or hypoxia for $24 \mathrm{~h}$. Results represent the average \pm S.D. of two independent experiments. $P$-values were calculated from control and wt or BH4-deleted bcl-2-overexpressing cells exposed at the same experimental conditions $\left({ }^{*} P<0.01\right)$
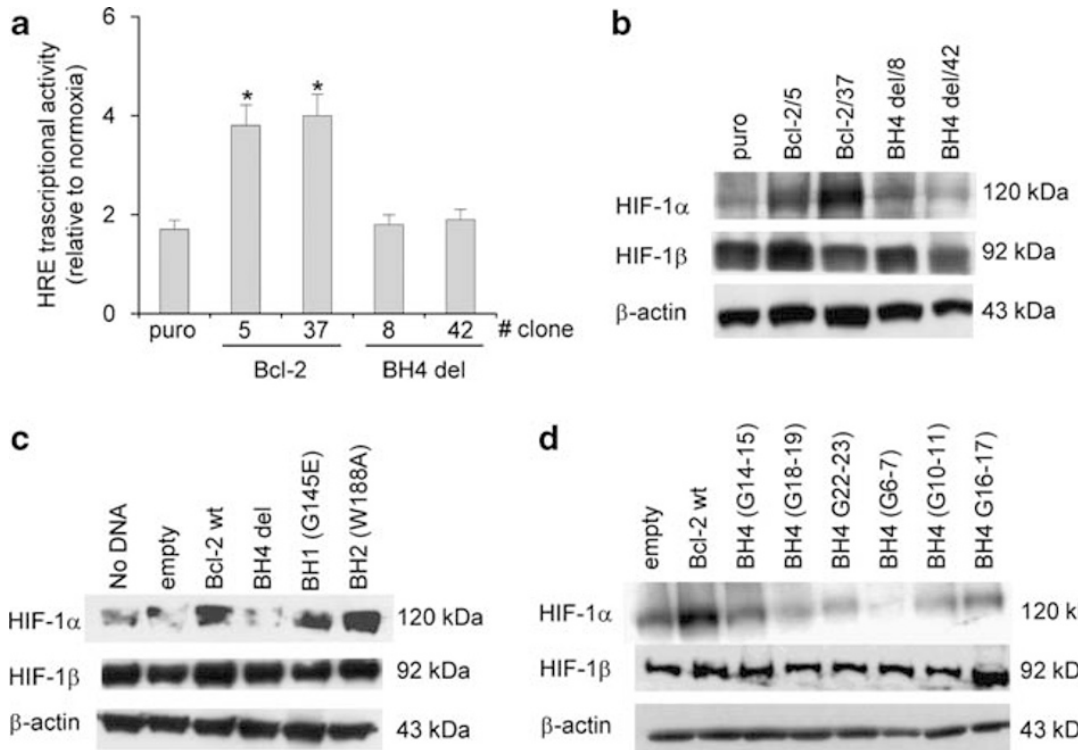

d
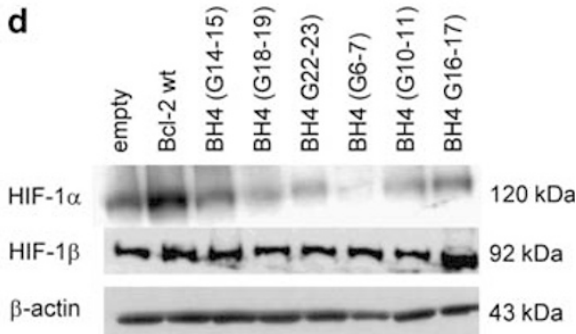

Figure 4 The $\mathrm{BH} 4$ domain is necessary for HIF-1 protein expression and activity induced by wild-type (wt) bcl-2 under hypoxia. (a) Hypoxic responsive element (HRE)-dependent transcriptional activity in a control clone (puro), clones overexpressing bcl-2 wt (Bcl-2/5, Bcl-2/37) or deleted of the $\mathrm{BH} 4 \mathrm{domain}(\mathrm{BH} 4 \mathrm{del} / 8, \mathrm{BH} 4 \mathrm{del} / 42)$. The luciferase construct containing the HIF-1-like (808-bp) consensus sequence was transiently transfected into cells and then exposed to normoxia or hypoxia for $24 \mathrm{~h}$. Luciferase values were normalized for transfection efficiency (luciferase/ $\beta$ galactosidase ratios). The results are reported as fold induction relative to normoxia and represent the average \pm S.D. of three independent experiments. $P$-values were calculated between control and wt or deleted bcl-2-overexpressing cells $\left({ }^{*} P<0.01\right)$. (b-d) Western blot analyses of HIF- $1 \alpha$ and HIF-1 $\beta$ protein expression in the nuclear $(\mathbf{b})$ or total ( $\mathbf{c}$ and $\mathbf{d}$ ) extracts of stably transfected M14-derived clones (b) or transiently transfected M14 cells (c and d) exposed to hypoxia for $24 \mathrm{~h}$. (c and d) Expression vectors encoding bcl-2 wt (Bcl-2 wt) or mutants at residues into the BH1 (G145E), the BH2 (W188A), the BH4 domain (G14-15; G18-19; G22-23; G6-7; G10-11; and G16-17), and bcl-2 deleted of the BH4 domain (BH4 del) were used. The untransfected (no DNA) and the control vector transfected (empty) M14 cells were used as control. Western blots representative of three independent experiments with similar results are shown. $\beta$-actin is shown as loading and transferring control 
dependent decrease in HIF-1 $\alpha$ protein level was observed in the cells after treatment with the protein synthesis inhibitor cyclohexamide ( $\mathrm{CHX})$ following hypoxia. Densitometric analysis revealed that, as previously reported, ${ }^{21}$ bcl-2 overexpression increased the HIF-1 $\alpha$ protein half-life from $15 \pm 5$ to $45 \pm 5 \mathrm{~min}$ under hypoxic conditions. By contrast, no significant difference in the HIF-1 $\alpha$ protein half-life was

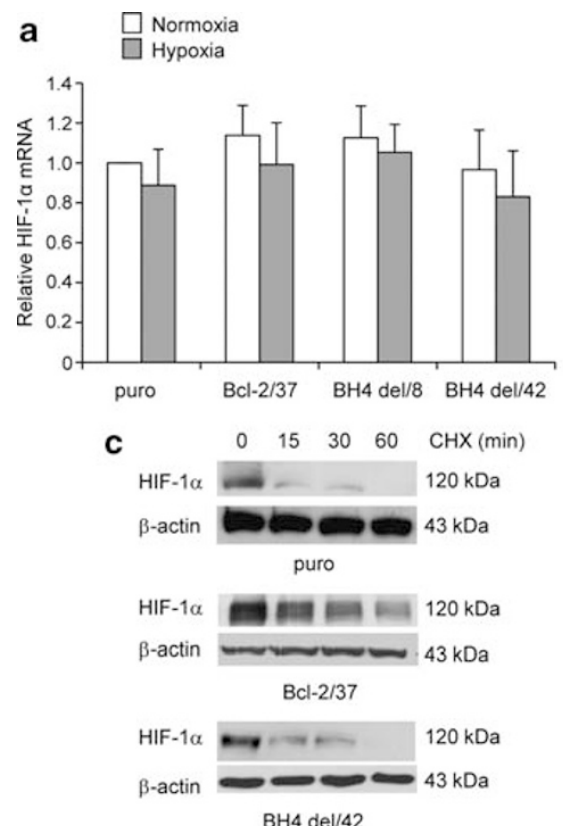

observed between control and stable clones expressing bcl-2 deleted of its $\mathrm{BH} 4$ domain (HIF- $1 \alpha$ protein half-life: $13 \pm 7 \mathrm{~min}$ ). Similarly, while a reduced HIF-1 $\alpha$ ubiquitination was observed in transfectants expressing $w t$ bcl-2, when compared with control cells, similar modulation of HIF-1 $\alpha$ ubiquitination was observed in transfectants carrying the deletion of $\mathrm{BH} 4$ domain and control cells (Figure $5 \mathrm{e}$ ).

b
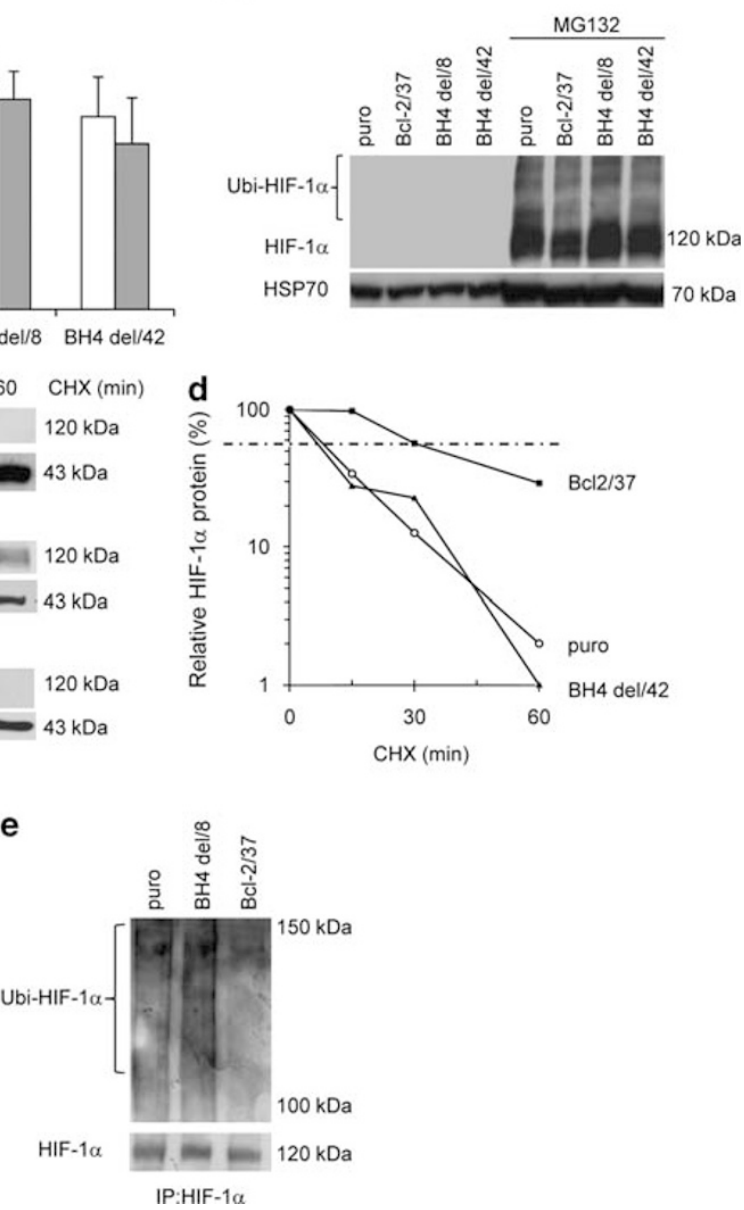

Figure 5 The BH4 domain is necessary for HIF-1 $\alpha$ protein stabilization by wild-type (wt) bcl-2. (a) RT-PCR evaluation of HIF-1 $\alpha$ mRNA level, (b and $\mathbf{c}$ ) western blot analyses of HIF-1 $\alpha$ protein expression after the exposure to MG132 proteosomal inhibitor $(10 \mu \mathrm{M})$ for $6 \mathrm{~h}$ in normoxic conditions $(\mathbf{b})$, or to hypoxia for $24 \mathrm{~h}$ followed by $\mathrm{CHX}$ treatment $(50 \mu \mathrm{g} / \mathrm{ml}$ ) for the indicated times (c) of M14 melanoma control (puro), a clone-overexpressing wt bcl-2 (Bcl-2/37), or bcl-2 deleted of the BH4 domain (BH4 del/8, $\mathrm{BH} 4$ del/42). (a) Values are expressed as means \pm S.D. of fold induction versus control cells (puro) exposed to normoxia. Results represent the average \pm S.D. of three independent experiments. (b and $\mathbf{c}$ ) Western blots representative of three independent experiments with similar results are shown. $\beta$-actin and HSP70 proteins are shown as loading and transfering control. (d) Densitometric analysis of the HIF-1 $\alpha$ protein level showed in western blot (c) was performed using Molecular Analyst Software and normalized to $\beta$-actin expression. Values are expressed as percentage of HIF- $1 \alpha$ protein after $\mathrm{CHX}$ treatment versus HIF- $1 \alpha$ protein expression in untreated cells (100\%). (e) Western blot analysis of HIF-1 $\alpha$ ubiquitination on control, bcl-2 wt and bcl-2 deleted of the BH4 domain cells after exposure to hypoxia. Whole cell lysates were immunoprecipitated (IP) with anti-HIF-1 $\alpha$ antibody and then western blot analysis was performed using anti-ubiquitin antibody

Figure 6 The effect of bcl-2 mutations on HIF-1/VEGF signaling is independent of their impact in bcl-2-mediated antiapoptotic function. (a) Cytofluorimetric dot plot analysis of the annexin V-FITC versus propidium iodide (PI) staining performed on M14 cells transiently transfected with several bcl-2 expression vectors. After transfection, cells were exposed to normoxia (untreated), hypoxia for $24 \mathrm{~h}$ or treated with CPT $(0.5 \mu \mathrm{M}$ for $48 \mathrm{~h})$. A representative experiment out of three performed with similar results is shown. Annexin $\mathrm{V}^{+} / \mathrm{PI}^{-}$and annexin $\mathrm{V}^{+} / \mathrm{PI}^{+}$were considered early and late apoptotic cells, respectively. (b) Percentage of annexin $\mathrm{V}^{+} / \mathrm{PI}^{-}\left(\mathrm{black}\right.$ bars) and annexin $\mathrm{V}^{+} /$ $\mathrm{PI}^{+}$(white bars) cells was calculated by cytofluorimetric analysis showed in Figure 6a using CellQuest Software (Becton Dickinson Immunocytometry Systems, San Jose, CA, USA). (c) Western blot analysis of PARP cleavage on the untransfected or transiently transfected cells treated with CPT $(0.5 \mu \mathrm{M}$ for $48 \mathrm{~h})$. Western blots representative of three independent experiments with similar results are shown. $\beta$-actin is shown as loading and transferring control. (a-c) Expression vectors encoding bcl-2 wild-type (Bcl-2 wt) or mutants at the residues into BH1 (G145E), the BH2 (W188A), at the BH4 domain (G14-15; G18-19; G22-23; G6-7; G10-11; and G16-17), or bcl-2 deleted of the BH4, $\mathrm{BH} 1, \mathrm{BH} 2$ domain (BH4 del, BH1 del, BH2 del) were used. The untransfected (no DNA) and the control vector transfected (empty) M14 cells were used as control 

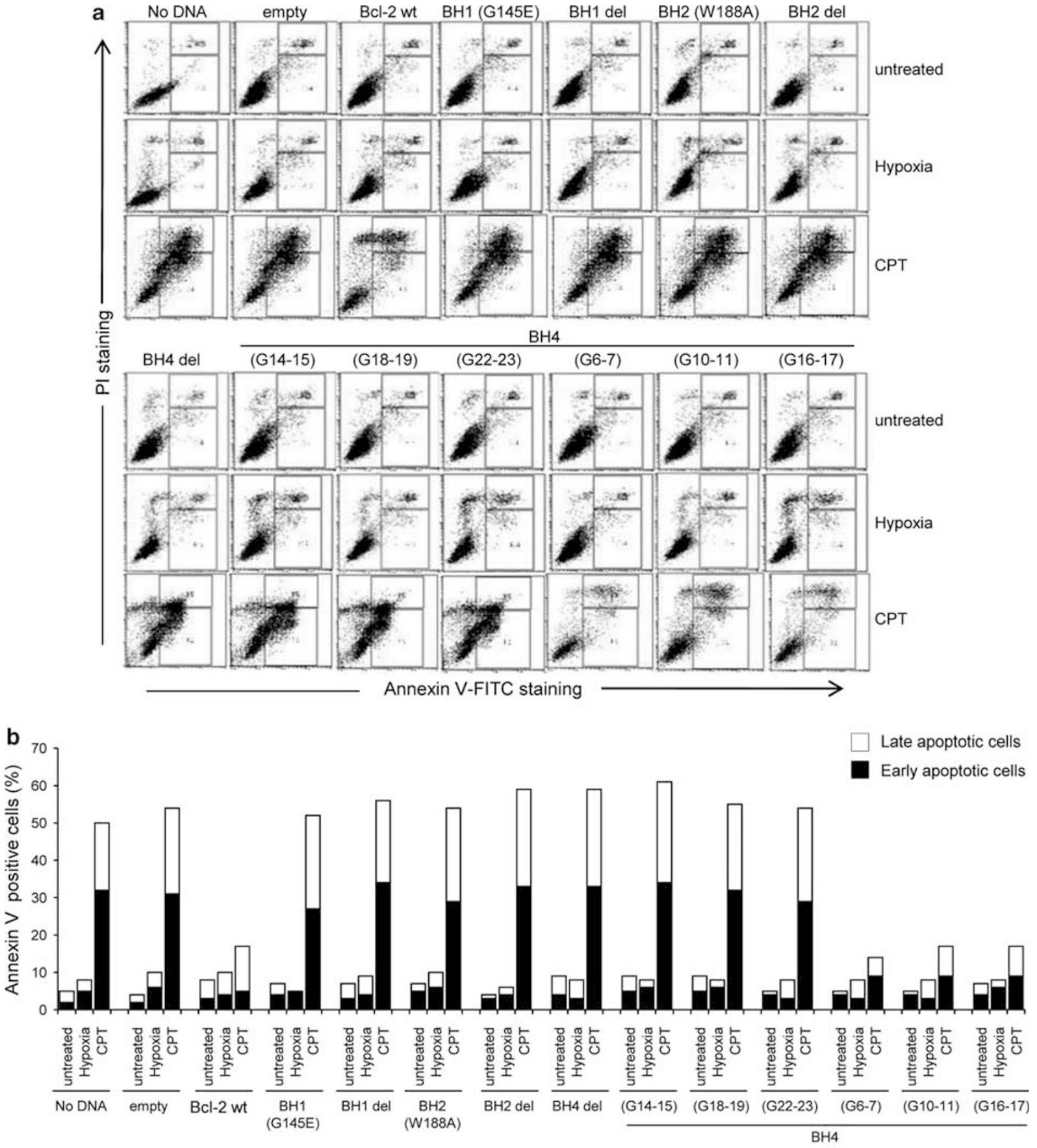

C

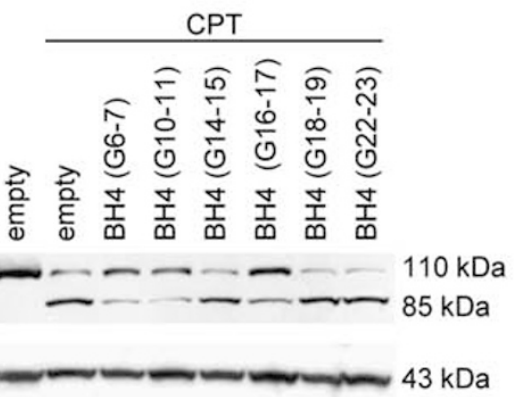


The effect of bcl-2 mutations on HIF-1/VEGF signaling is independent of their relevance in apoptosis. To exclude the possibility that the effect of bcl-2 on HIF-1/VEGF expression and activation could be a consequence of a different modulation of the apoptotic pathway by ectopic expression of different forms of bcl-2, we evaluated the response of cells to camptothecin (CPT), a drug able to activate the apoptotic program in several experimental models, ${ }^{22}$ (Figures $6 \mathrm{a}$ and b). CPT treatment induced about $50 \%$ of apoptosis in untransfected cells or cells transfected with empty vector, while it induced a very low percentage of apoptosis in cells overexpressing wt bcl-2. CPT-induced apoptosis was also observed in cells transfected with expression vectors encoding $\mathrm{BH} 1, \mathrm{BH} 2$ and $\mathrm{BH} 4$ domain deletion mutants of bcl-2, bcl-2 single-point mutants of highly conserved residues within the $\mathrm{BH} 1$ (G145E) or BH2 (W188A) domains, or dicodon mutants into the BH4 domain (G14-15, G18-19 and G22-23). On the other hand, the rate of apoptotic events in the cells transfected with bcl-2 mutations into the residues 6-7, 10-11 and 16-17 of $\mathrm{BH} 4$ domain was quite similar to that observed following CPT treatment in cells overexpressing $w t$ bcl-2, confirming that these residues are not required for bcl-2 antiapoptotic activity. ${ }^{6,7,23}$ These results were also confirmed by the cleavage of poly(ADP-ribose) polymerase (PARP) after treatment with CPT (Figure 6c) in cells expressing bcl-2 deleted in $\mathrm{BH} 4$ domain but not in cells overexpressing $w t$ bcl-2. Further, PARP cleavage was markedly reduced in the cells overexpressing bcl-2 protein mutated into amino acids $6-7,10-11$ and 16-17 within $\mathrm{BH} 4$ domain. Next, we evaluated whether mutated bcl-2 protein induced cell death and reactive oxygen species (ROS) production under hypoxia. The exposure of cells to hypoxia for $24 \mathrm{~h}$ did not induce either apoptosis (Figures $6 \mathrm{a}$ and $b$ ) or the generation of ROS (Supplementary Figure 1) either in control or in cells overexpressing wt or mutated bcl-2. In all cells, $<10 \%$ of apoptosis and $<5 \%$ of ROS were observed after $24 \mathrm{~h}$ exposure to hypoxia regardless bcl-2 status.

TAT-BH4 peptide alone is sufficient to enhance HIF-1/ VEGF axis. To confirm the hypothesis that the $\mathrm{BH} 4$ domain has a role in the hypoxic induction of HIF-1/VEGF by bcl-2, we determined whether the exogenous application of TAT-BH4 peptide is able to modulate HIF-1/VEGF axis in M14 cells. First, to confirm the antiapoptotic activity of TAT-BH4 peptide, ${ }^{24,25}$ we evaluated the response of M14 cells to CPT. Figure 7a showed that the addition of TAT-BH4 significantly decreased the percentage of apoptosis induced by CPT: approximately 30 and $11 \%$ early apoptotic cells were observed after treatment with CPT in presence of control (TAT-CTRL) or TAT-BH4 peptides, respectively. Further, we also tested the effect on VEGF/HIF-1 signaling of a mutant version of TAT-BH4. The percentage of early apoptotic events in the cells treated with CPT and exposed to the mutant version of TAT-BH4 was quite similar to that observed after treatment with CPT and TAT-BH4 peptide, confirming that mutant version of TAT-BH4 still retains the antiapoptotic activity showed by TAT-BH4 (Figure 7a). The exogenous application of TAT-BH4 peptide increased the level of secreted VEGF protein (Figure 7b), VEGF promoter activity (Figure 7c), HIF-1 transcriptional activity (Figure 7d) and HIF-1 $\alpha$ protein levels (Figure 7e) in the M14 cells when compared with the untreated or TAT-CTRLtreated cells only after exposure to hypoxia. On the contrary, these parameters were not affected by the treatment with the mutant version of TAT-BH4. Similar results in terms of VEGF and HIF- $1 \alpha$ protein induction were also obtained using a BH4 antiapoptotic peptide ${ }^{25}$ from bcl-xL (data not shown). Finally, exogenous application of TAT-BH4 peptide increases HIF-1 $\alpha$ protein half-life (Figure $7 f$ ) and reduces HIF-1 $\alpha$ protein ubiquitination under hypoxic conditions (Figure 7g).

As we have obtained evidence that the localization of bcl-2 protein is important for its effect on HIF-1/VEGF signaling, ${ }^{21}$ we evaluated the presence of TAT-BH4 peptide in the cellular compartments where generally bcl-2 protein localizes, ${ }^{26}$ and the possible effect of hypoxia on TAT-BH4 localization by using a labeled version of peptide. First, we confirmed by flow cytometric (Figure 8a) and confocal microscopy (Figure 8b) analyses the efficient incorporation of TAT-BH4 peptide into the cells. Using different organelle-specific labeling, we found that TAT-BH4 peptide did not reside in the classical compartments in which full-length bcl-2 is generally found, such as nucleus, mitochondria or endoplasmic reticulum in normoxic conditions, and hypoxia did not alter this localization of TAT-BH4.

The effect of BH4 domain on HIF-1/VEGF pathway activation is independent from the presence of endogenous bcl-2 protein. To test whether in our model the overexpression of bcl-2 deleted of $\mathrm{BH} 4$ domain protein could suppress the activity of endogenous protein, bcl-2 wt or deleted of its $\mathrm{BH} 4$ domain was stably expressed in HT29 cells that do not express detectable levels of endogenous bcl-2, ${ }^{27}$ as confirmed by western blot and RT-PCR analyses (Supplementary Figure 2). As shown in Figures 9a and b, wt bcl-2-overexpressing HT29 cells exposed to hypoxia for $24 \mathrm{~h}$ secrete higher level of VEGF protein than the parental cells. Both HT29 clones carrying bcl-2 deleted of the $\mathrm{BH} 4$ domain expressed VEGF protein at a level that is comparable to the one of control cells. Next, we evaluated whether exogenous application of TAT-BH4 peptide is sufficient to enhance HIF-1/VEGF axis also in a context of bcl-2-deficient background. An increase in both VEGF (Figures 9c and d) and HIF-1 $\alpha$ (Figure 9d) protein levels in HT29 cells was observed after hypoxic exposure to TAT-BH4 peptide when compared with untreated cells. Both VEGF promoter and HIF-1-dependent transcriptional activity were also increased after the treatment of HT29 cells with TAT-BH4 peptide, under hypoxic conditions (data not shown).

\section{Discussion}

In this study, we investigated the possible role of the $\mathrm{BH} 1$, $\mathrm{BH} 2$ and $\mathrm{BH} 4$ domains of bcl-2 protein in the regulation of HIF-1-mediated VEGF expression under hypoxia. We demonstrated that the deletion of the $\mathrm{BH} 4$ domain abrogated the ability of bcl-2 to cooperate with hypoxia to induce VEGF protein expression in tumor cells with different origin. The 


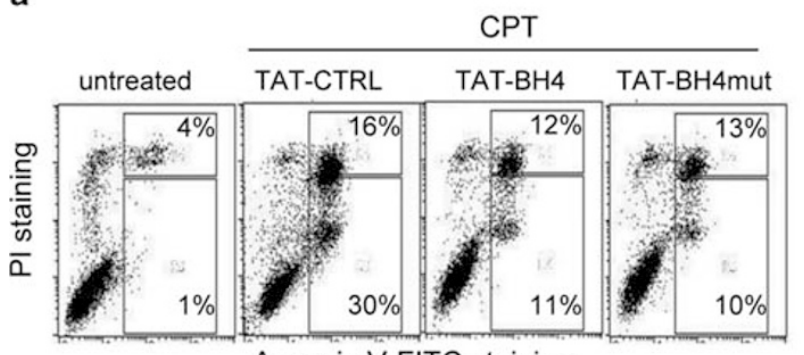

Annexin V-FITC staining
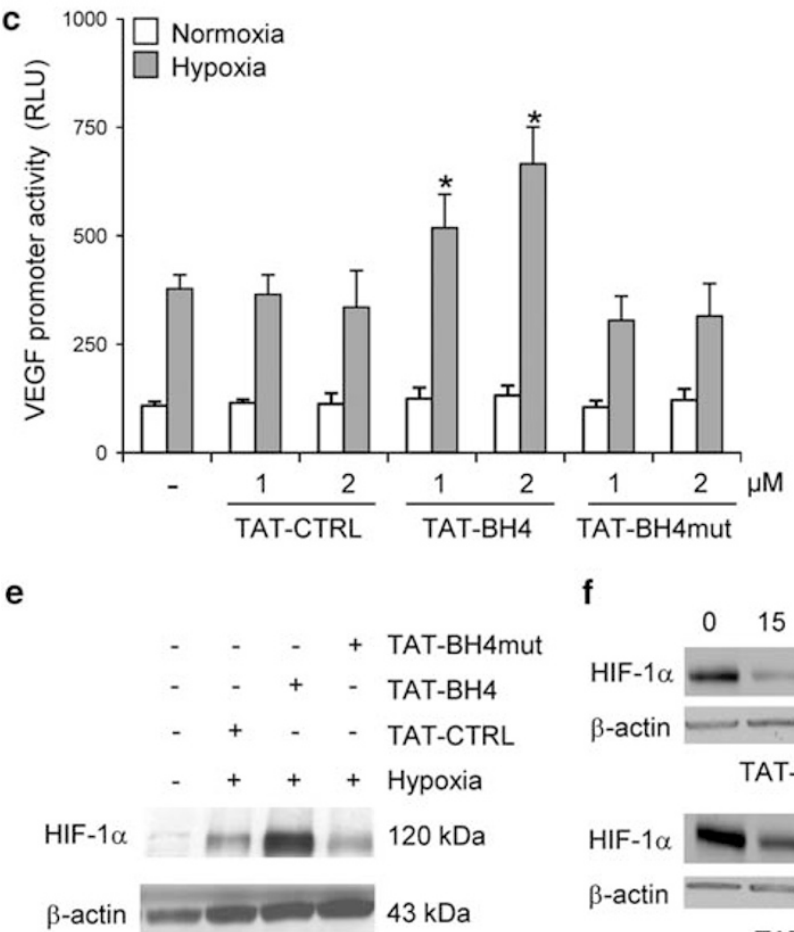

f
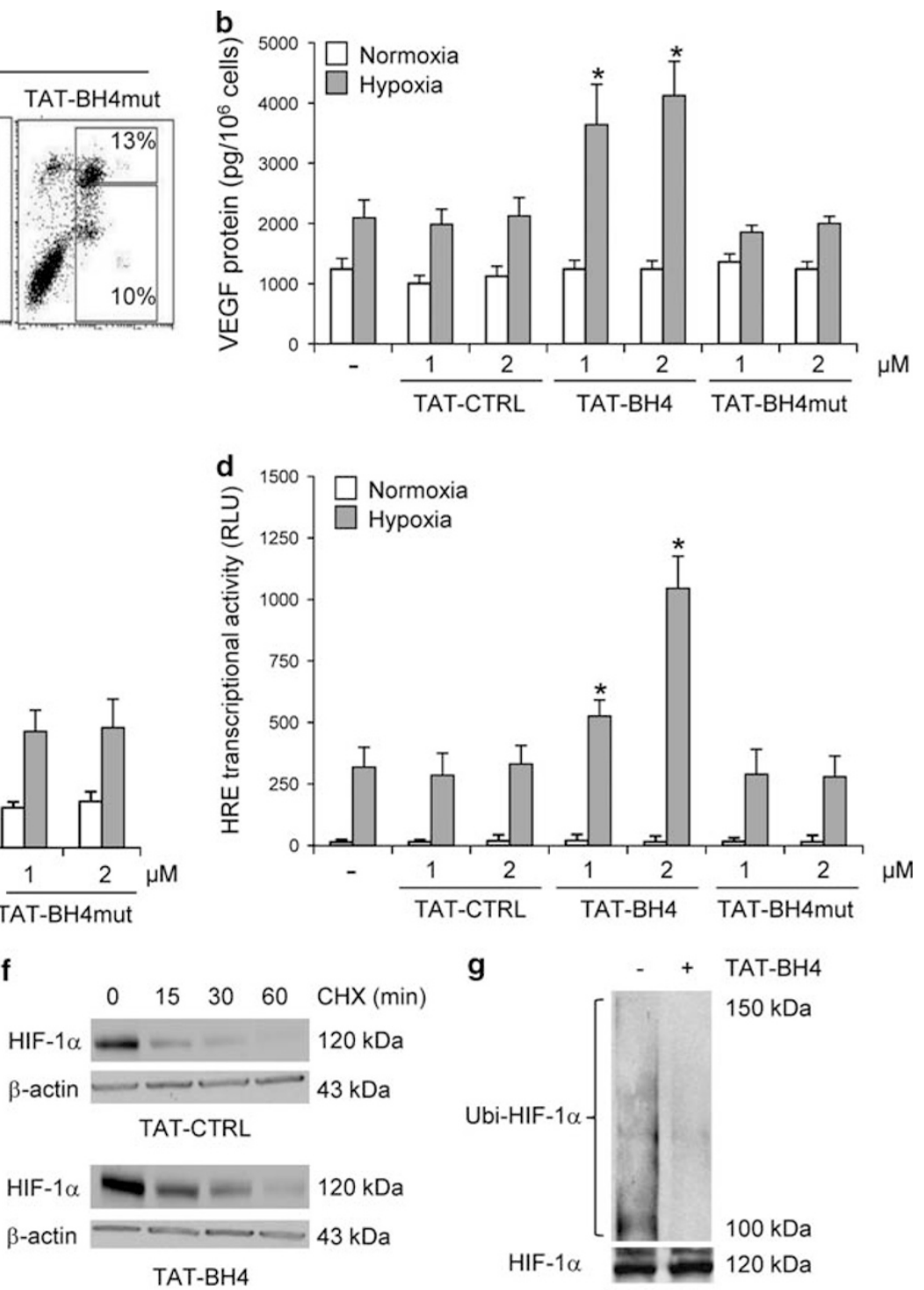

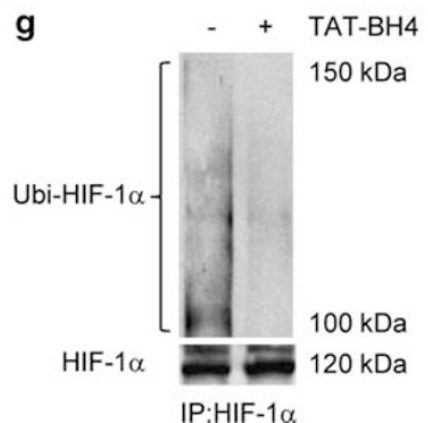

g

IP:HIF-10

Figure 7 VEGF protein expression is induced under hypoxia by exogenous application of the TAT-BH4 cell permeable peptide in M14 cells. (a) Cytofluorimetric dot plot analysis of the annexin V-FITC versus propidium iodide (PI) staining performed on M14 control cells (untreated), or treated with CPT ( $0.5 \mu \mathrm{M}$ for $48 \mathrm{~h}$ ) in presence of the different peptides $(2 \mu \mathrm{M})$. The percentage of the annexin $\mathrm{V}^{+} / \mathrm{PI}^{-}$(early apoptotic cells) and annexin $\mathrm{V}^{+} / \mathrm{PI}^{+}$(late apoptotic cells) are shown. Each panel is representative of three separate experiments with comparable results. (b) VEGF protein expression evaluated by ELISA, (c) VEGF promoter activity, (d) hypoxic responsive element (HRE) transcriptional activity in M14 cells after exposure to hypoxia in presence of different peptides at the indicated concentrations. (c and d) The luciferase constructs containing the VEGF 1511-bp proximal promoter (c) or HIF-1-like (808-bp) (d) consensus sequences were transiently transfected and then cells were treated with peptides under hypoxia for $24 \mathrm{~h}$. Luciferase values were normalized for transfection efficiency (luciferase/ $\beta$ galactosidase ratios). RLU, relative luciferase unit. The results are reported as the average \pm S.D. of three independent experiments. $P$-values were calculated between control and treated cells exposed to hypoxia $\left({ }^{*} P<0.01\right)$. (e) Westem blot analysis of HIF-1 $\alpha$ protein in total cell extracts of M14 cells after exposure to hypoxia in presence of different peptides $(2 \mu \mathrm{M})$. (f) Westem blot analysis of HIF-1 $\alpha$ protein on M14 cells after exposure to hypoxia in presence of peptides and then followed by $\mathrm{CHX}$ ( $50 \mu \mathrm{g} / \mathrm{ml})$ treatment for the indicated times. (g) Western blot analysis of HIF-1 $\alpha$ ubiquitination after exposure of M14 cells to hypoxia in the presence or absence of TAT-BH4 peptide. Whole cell lysates were immunoprecipitated (IP) with anti-HIF-1 $\alpha$ antibody and then western blot analysis was performed using anti-Ubiquitin antibody. (e and $\mathbf{f}$ ) Western blots representative of two independent experiments with similar results are shown. $\beta$-actin is shown as loading and transferring control. (a-g) TAT-CTRL (control peptide), TAT-BH4 (peptide corresponding to wild-type BH4 domain of bcl-2) and TAT-BH4mut (peptide corresponding to a mutated versions of BH4 domain into amino acids 6-7) were used

relevance of $\mathrm{BH} 4$ domain on the regulation of HIF-1/VEGF axis under hypoxia was showed in a human melanoma model. In particular, deletion of or point mutations into the $\mathrm{BH} 4$ region resulted in impaired ability of $w t$ bcl-2 protein to induce VEGF promoter activity, HIF-1 $\alpha$ protein stabilization and ubiquitination under hypoxia.
$\mathrm{BH} 4$ is one of the principal domains for the full multifunctional ability of bcl-2, and it appears to mediate the antiapoptotic activity of bcl-2 independently from the interaction of this protein with other bcl-2 family members. The $\mathrm{BH} 4$ domain is necessary and sufficient for bcl-2 to prevent apoptosis, bind to bax, translocate into the nucleus, 


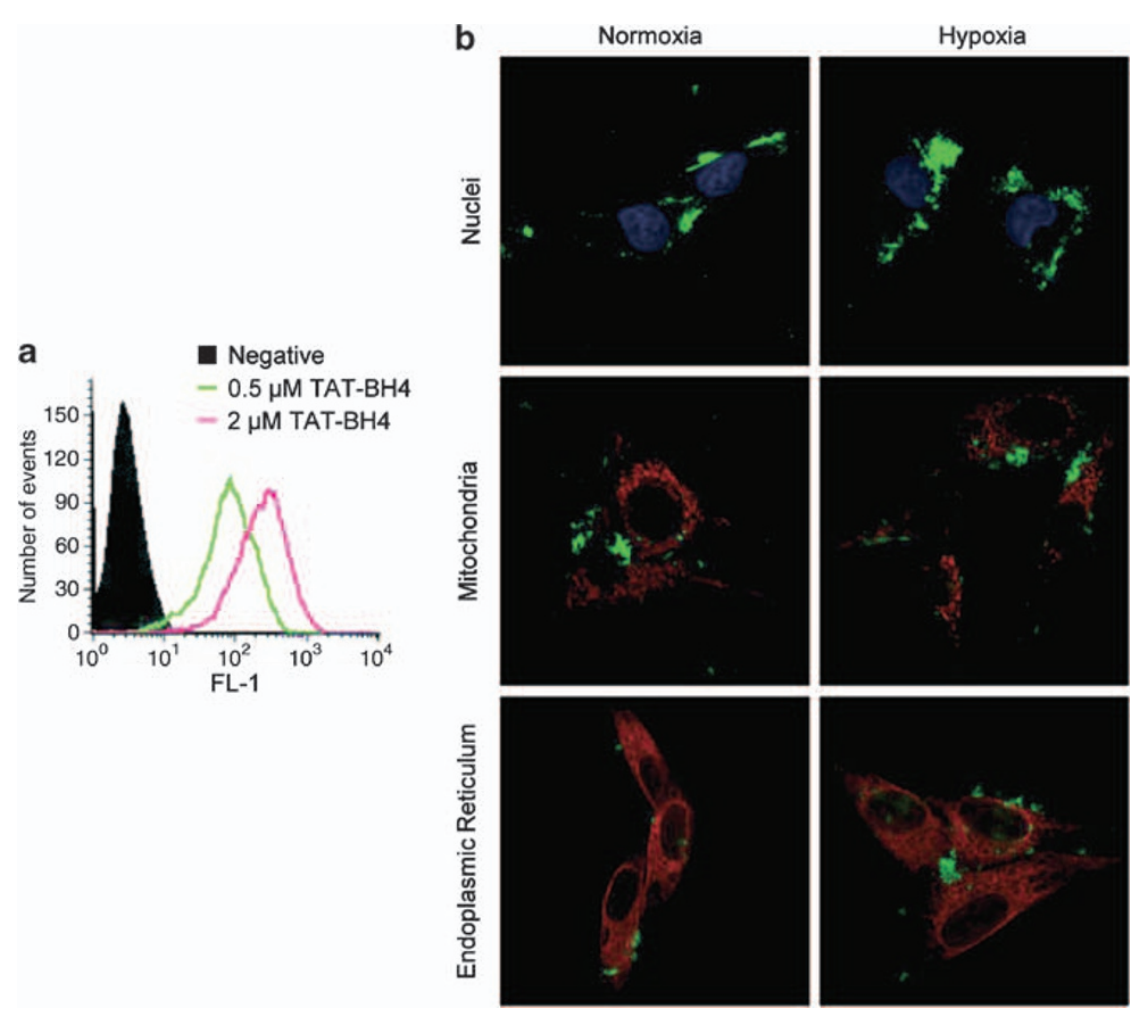

Figure 8 Cellular localization of TAT-BH4 peptide in M14 cells exposed to normoxia or hypoxia. (a) Cytofluorimetric evaluation of TAT-BH4 peptide incorporation in M14 cells treated with 0,5 and $2 \mu \mathrm{M}$ of peptide. (b) Confocal laser scanning microscopy of immunofluorescence staining performed on M14 cells exposed to hypoxia or normoxia for $24 \mathrm{~h}$, in the presence of TAT-BH4 peptide (green). Fixed cells were labeled with nuclear staining TO-PRO3 (blue), mitochondrial-specific anti-HSP60 antibody (red) or endoplasmic reticulum-specific anti-calreticulin antibody (red)

reduce cell proliferation, induce nuclear factor-kappa $B$ activity and regulate DNA repair. ${ }^{4,5,28}$ In addition, some authors have suggested that bcl-2 deleted of its $\mathrm{BH} 4$ domain functions like bax to promote, rather than inhibit, cell death, ${ }^{6}$ while other groups have reported that $\mathrm{BH} 4$ deletion converts bcl-2 into a dominant-negative inhibitor of bcl-2. ${ }^{7}$ In our experimental model, the bcl-2 protein deleted of $\mathrm{BH} 4$ domain did not function as a dominant-negative inhibitor toward the bcl-2 ability to protect from apoptosis. In fact, cells overexpressing bcl-2 protein, whose $\mathrm{BH} 4$ domain was deleted or presented point mutations, undergo to apoptosis after treatment with CPT, a drug able to induce apoptotic cell death in parental but not in bcl-2 wt overexpressing cells.

The molecular mechanism by which bcl-2 increases HIF-1mediated VEGF expression in melanoma cells under hypoxia might be found in the ability of $\mathrm{BH} 4$ domain to directly or indirectly interact with $\mathrm{HIF}-1 \alpha$ protein, or to modulate the activity of some proteins found to interact with the $\mathrm{BH} 4$ region. ${ }^{4,5,29-33}$ Moreover, some bcl-2 protein interactors, such as the bcl-2 mitochondrial chaperone FKBP38, the orphan nuclear receptor Nur77 and the molecular chaperone HSP90, have been demonstrated to be involved in oxygen-dependent and -independent regulation of the HIF-1 $\alpha$ protein. ${ }^{33-35}$ Even if we recently demonstrated that bcl-2 protein under hypoxic conditions interacts with both HIF- $1 \alpha$ and HSP90 proteins contributing to the enhancement of HIF- $1 \alpha$ protein stability, ${ }^{21}$ we cannot exclude that also other bcl-2 interactors can be involved in bcl-2-induced HIF-1 $\alpha /$ VEGF regulation.

We have also observed that TAT-BH4 peptide in hypoxic melanoma cells acts like full-length $w t$ bcl-2 mimicking bcl-2 functions in terms of HIF-1/VEGF regulation. In fact, we showed that the TAT-BH4 peptide had a significant effect on VEGF protein induction and promoter activity, and regulated HIF-1 $\alpha$ protein expression increasing the half-life and decreasing the ubiquitination of the protein. Our results clearly indicate that the $\mathrm{BH} 4$ domain is sufficient to induce HIF-1mediated VEGF protein expression under hypoxia. TATcontrol as well as TAT-BH4 mutant peptides showed no such effects, confirming the specific effect of TAT-BH4 peptide. Further, TAT-BH4 peptide localization was not responsible of the effects exerted by the peptide under hypoxic condition, in fact similar localization in the cytosol was found regardless oxygen tension. Our results also demonstrated that amino acidic residues within $\mathrm{BH} 1$ or $\mathrm{BH} 2$ domains required for the antiapoptotic activity of bcl-2 are not indispensable for bcl-2dependent HIF-1/VEGF induction under hypoxia. In fact, bcl-2 protein deleted in $\mathrm{BH} 1$ or $\mathrm{BH} 2$ domains is still able to cooperate with hypoxia to activate HIF-1/VEGF signaling, as observed for $w t \mathrm{bcl}-2$, despite the lower deleted protein levels showed by the cells overexpressing $\mathrm{BH} 1$ and $\mathrm{BH} 2$ mutants in comparison with $w t$ bcl-2-overexpressing cells. So this finding indicates that those low levels of $\mathrm{BH} 1 / \mathrm{BH} 2$ deleted proteins 

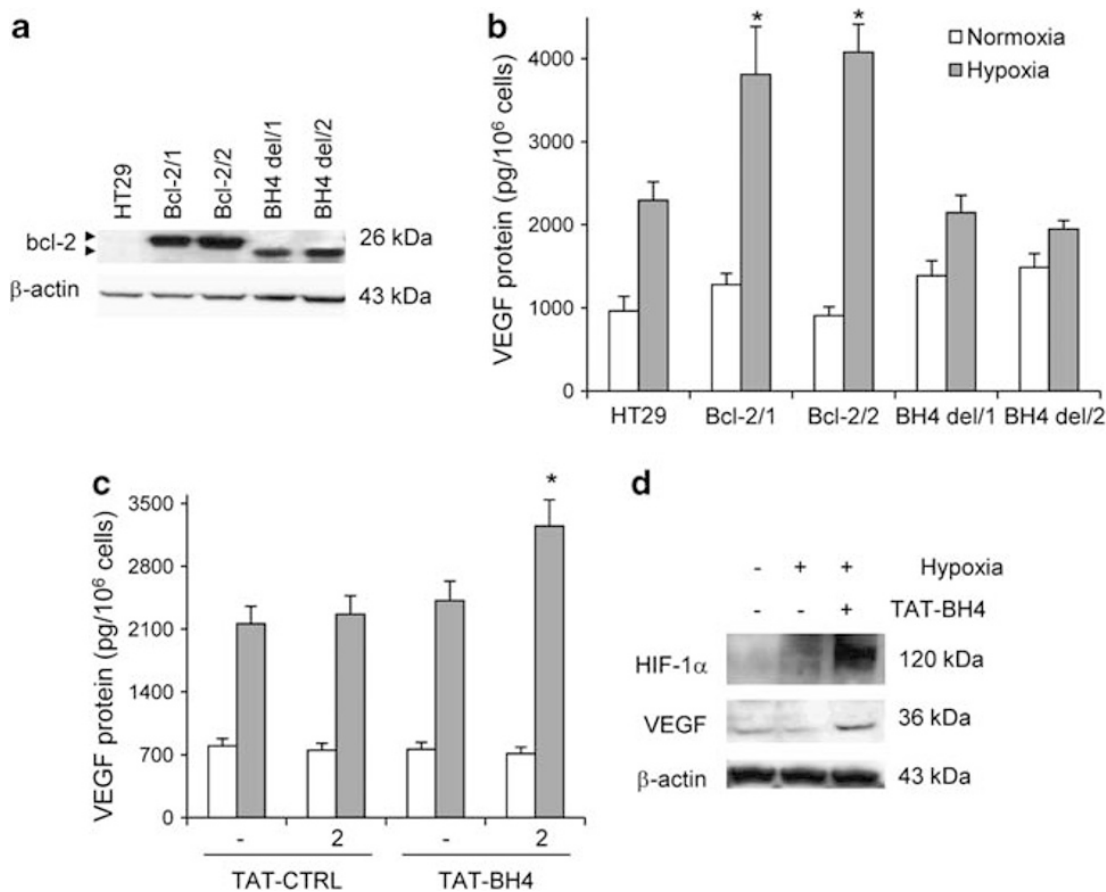

d

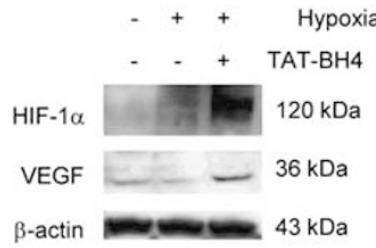

Figure $9 \mathrm{Bcl}-2$ deleted of its $\mathrm{BH} 4$ domain is not a dominant-negative inhibitor of the endogenous wild-type (wt) bcl-2 protein. (a) Western blot analysis of bcl-2 protein expression, and (b)VEGF protein expression evaluated by ELISA in HT29 colon carcinoma cell line and its derivative clones overexpressing wtbcl-2 (Bcl-2/1, Bcl-2/2), or bcl-2 deleted of the BH4 domain (BH4 del/1, BH4 del/2). (c) VEGF protein expression evaluated by ELISA, and (d) western blot analysis of HIF-1 $\alpha$ and VEGF proteins in HT29 cells after exposure to hypoxia in presence of $2 \mu \mathrm{M}$ TAT-BH4 or TAT-CTRL as control. (a and d) Western blot representative of three independent experiments with similar results are shown. $\beta$-actin is shown as loading and transferring control. (b and $\mathbf{c}$ ) Results represent the average \pm S.D. of three independent experiments. (b) $P$-values were calculated from control and wt or mutated bcl-2-overexpressing cells exposed at the same experimental conditions $\left({ }^{*} P<0.01\right)$. (c) $P$-values were calculated between control and TAT-BH4-treated cells exposed to hypoxia $\left({ }^{*} P<0.01\right)$

are sufficient to sustain HIF-1/VEGF pathway activation in hypoxia. The fact that the level of $\mathrm{BH} 4$ deleted protein obtained after overexpression is comparable with the ones of cells expressing $\mathrm{BH} 1 / \mathrm{BH} 2$ deleted bcl-2 protein, is an indirect demonstration that the loss of bcl-2 activity showed after $\mathrm{BH} 4$ domain deletion is not due to the lower level of expression of bcl-2 mutated in comparison with $w t$ bcl-2 protein expression. This observation, as also demonstrated by other investigators, ${ }^{6}$ may be due to an higher stability of full-length $w t$ bcl-2 protein or to a different percentage of transfected cells.

The role of the $\mathrm{BH} 3$-driven protein-protein interaction on bcl-2-dependent regulation of HIF-1/VEGF was excluded by using HA14-1, a BH3 mimetic antagonist of bcl-2 (Supplementary Figure 3). Exposure of bcl-2-overexpressing cells to HA14-1 did not affect the increased expression of VEGF observed after hypoxic exposure of bcl-2 transfectants, thus indicating that bcl-2-induced HIF1/VEGF pathway is not related to the ability of bcl-2 to interact with the $\mathrm{BH} 3$ domain of proapoptotic proteins. By other hand, mutations of bcl-2 protein into $\mathrm{BH} 1$ (G145E), BH2 (W188A) and BH4 (G14-15) domains, disrupting the heterodimerization of bcl-2 with $\mathrm{BH} 3-$ containing pro-apoptotic proteins, confirm these results. In fact, although all these mutations damp bcl-2 antiapoptotic activity, only $\mathrm{BH} 4$ (G14-15) mutant affects bcl-2-induced VEGF/HIF1 expression and activity. Also the evidence that mutations on all the analyzed residues into $\mathrm{BH} 4$ abrogated bcl-2 ability to induce HIF-1/VEGF signaling under hypoxia, whereas they differently affect bcl-2 ability to prevent apoptosis, sustained our hypothesis that the antiapoptotic function of bcl-2 is not required for its effect on angiogenesis. These results were also corroborated by the evidence that TAT-BH4 mutated peptide that still retains antiapoptotic effect, is not able to activate HIF-1/VEGF signaling. We further excluded the possibility that the effect of bcl-2 on the VEGF/HIF-1 pathway was attributed to the activity of bcl-2 as a prosurvival and antiapoptotic protein, because transient transfection of wt or mutated bcl-2 proteins did not induce 'per se' cell death in our experimental model, and $<10 \%$ of apoptotic cells were observed in all the cell lines tested at the end of hypoxia exposure, regardless bcl-2 status expression.

By using the HT29 colon carcinoma cell line, which is deficient for bcl-2 expression, ${ }^{27}$ we have also showed that bcl-2 deleted of its $\mathrm{BH} 4$ domain is not a dominant-negative inhibitor of endogenous bcl-2 protein in terms of VEGF expression. In the same context of bcl-2-deficient background, the application of TAT-BH4 peptide is sufficient to enhance HIF-1/VEGF axis. Thus, demonstrating that the effect of $\mathrm{BH} 4$ domain is not mediated by the presence of endogenous bcl-2 protein.

In summary, our results demonstrate that the ability of $w t$ $\mathrm{bcl}-2$ to enhance angiogenesis through the $\mathrm{BH} 4$ domain is not related to its role in preventing apoptosis, and indicate that the development of inhibitors based on the $\mathrm{BH} 4$ domain of bcl-2 can be useful to better define the functions of $\mathrm{BH} 4$ domain 
and for the treatment of tumors associated with increased expression of VEGF and/or HIF-1 $\alpha$ proteins.

\begin{abstract}
Materials and Methods
Cell cultures, reagents and transfections. Human M14, PLF2 and JR1 (melanoma), HT29 (colon carcinoma), CaOV3 (ovarian carcinoma) and H1299 (lung carcinoma) were cultured in 10\% FBS RPMI medium (Invitrogen, Carlsbad, CA, USA). The cells were stably or transiently transfected with the expression vectors encoding the human wt bcl-2 or different bcl-2 mutants (Figure 1a). Transfections of expression vectors and hypoxia treatment were performed as previously reported. ${ }^{11}$ Two wt bcl-2-overexpressing (Bcl-2/clone 5 and Bcl-2/clone 37), two bcl-2 mutants at the BH1 domain (BH1(G145E)/clone 14 and BH1(G145E)/clone 25), at the $\mathrm{BH} 2$ domain $(\mathrm{BH} 2(\mathrm{~W} 188 \mathrm{~A}) /$ clone 6 and $\mathrm{BH} 2(\mathrm{~W} 188 \mathrm{~A}) /$ clone 16$)$, two bcl-2 deleted of the $\mathrm{BH} 4$ domain (BH4 del/clone 8 and $\mathrm{BH} 4$ del/clone 42) clones, a control clone (puro) derived from the M14 line after stable transfection were used. Stable clones were cultured in the presence of puromycin $(1 \mu \mathrm{g} / \mathrm{ml}$, Sigma-Aldrich, St. Louis, MI, USA). TAT-BH4 Bcl-2, a cell-penetrating peptide of human immunodeficiency virus TAT fused to a synthetic peptide corresponding to the BH4 domain (NH2-GRKKRRQRRRGGRTGYDNREIVMKYIHYKLSQRGYEW-COOH), TAT-BH4mut Bcl-2 peptide (NH2-GRKKRRQRRRGGGGGYDNREIVMKYIHYKLSQ RGYEW-COOH) corresponding to the mutated versions of $\mathrm{BH} 4$ (G6-7), and TAT-CTRL (NH2-RKKRRQRRRGGLKNDDICLRVYTPVSILVNE-COOH) peptide were obtained from PRIMM (Milan, Italy). For some experiments, TAT-BH4 peptide was labeled at amino-terminal with 5(6)-carboxyfluorescein. CPT, CHX, Z-leu-leu-leuCHO (MG132) were purchased from Sigma-Aldrich.
\end{abstract}

ELISA, western blot and flow cytometric analyses and promoter activity. ELISA, flow cytometric analysis and evaluation of promoter activity were done as previously reported. ${ }^{9,36}$ Nuclear and cytoplasmic fractions were prepared as previously reported. ${ }^{21}$ For immunoprecipitation assays and western blot analysis, the cells were lysed in CHAPS buffer ( $40 \mathrm{mM} \mathrm{HEPES} \mathrm{(pH} \mathrm{7.5),} 120 \mathrm{mM} \mathrm{NaCl}, 1 \mathrm{mM}$ EDTA, $10 \mathrm{mM}$ pyrophosphate, $10 \mathrm{mM}$ glycerophosphate, $50 \mathrm{mM} \mathrm{NaF}, 1.5 \mathrm{mM}$ $\mathrm{Na}_{3} \mathrm{VO}_{4}, 0.3 \%$ CHAPS, and one tablet EDTA-free protease inhibitors (Roche, Welwyn Garden City, UK) per $50 \mathrm{ml}$ ). Following centrifugation, the supernatant was precleared with protein $A / G$ agarose beads coupled with rabbit $\lg G$ for $>2 \mathrm{~h}$ and then $1 \mu \mathrm{g}$ of the HIF-1 $\alpha$ antibody (clone H-206, Santa Cruz Biotechnology, Santa Cruz, CA, USA) was added, and incubated overnight at $4^{\circ} \mathrm{C}$ with protein $\mathrm{A} / \mathrm{G}$ agarose beads (Amersham Biosciences Europe, Milan, Italy). Immunoprecipitates were washed four times in the lysis buffer before western blot analysis. For some immunoprecipitation experiments we used ExactaCruz reagents (Santa Cruz Biotecnology) to detect the bcl-2 protein without detection of the light chain of the immunoprecipitation antibody. Immunoprecipitations were also performed using multiple antibodies recognizing different epitopes on the bcl-2 (100, Santa Cruz Biotechnology) and HIF-1 $\alpha$ (Santa Cruz Biotecnology; Novus Biologicals, Littleton, CO, USA) proteins. Antibodies against HIF- $1 \alpha$ (clone 54, BD Pharmingen, San Jose, CA, USA), HIF-1 $\beta$ (clone 29, BD Pharmingen), PARP (clone 4C10-5, BD Pharmingen), bcl-2 (clones N-19 and C-2, Santa Cruz Biotechnology; clone 124, Dako, Milan, Italia), ubiquitin (clone P4G7, Santa Cruz Biotechnology), $\beta$-actin (clone AC-15, Sigma-Aldrich) and HSP72/73 (clone W27, Calbiochem, EMD Biosciences, La Jolla, CA, USA) were used.

Reverse transcriptase-polymerase chain reaction (RT-PCR). Total cellular RNA was isolated using Trizol reagent (Invitrogen). CDNA equivalent to $1 \mu \mathrm{g}$ of total RNA was generated by reverse transcription reaction using (oligo dT) ${ }_{18}$ primer (Fermentas, Burlington, Ontario, Canada) according to the manufacturer's instructions and then $2 \mu \mathrm{l}$ of obtained CDNA were added to PCR reaction mix (Fermentas) containing exon-specific primers targeting HIF- $1 \alpha$ (sense 5'-CCCAGATTCAGGATCAGACA-3', antisense 5'-CCATCATGTTCCATITTCGC-3') and $\beta$-actin (sense, $5^{\prime}$-AAGAGAGGCATCCTCACCCT- $3^{\prime}$, antisense $5^{\prime}$-ATCTCTTGCT CGAAGTCCAG- $3^{\prime}$ ) for 25 cycles with an annealing temperature of $56^{\circ} \mathrm{C}$. PCR products were separated by $1.5 \%$ agarose gel electrophoresis and gel was scanned with Gel Doc XR (Bio-Rad, Hercules, CA, USA). The intensity of the bands was quantified by densitometry using Molecular Analyst Software (Bio-Rad) and the optical density of each HIF- $1 \alpha$ amplified band was normalized to the intensity of each $\beta$-actin band.

Confocal analysis. Cells were treated with $0.5 \mu \mathrm{M}$ TAT-BH 4 peptide modified at amino-terminal with 5(6)-carboxyfluorescein and then exposed to normoxia or hypoxia. After $24 \mathrm{~h}$, cells were fixed in $3.7 \%$ formaldehyde for $15 \mathrm{~min}$ at room temperature, permeabilized with $0.2 \%$ Triton $\mathrm{X}-100$ in PBS for $10 \mathrm{~min}$ at room temperature and then incubated with anti-calreticulin (Affinity Bioreagents, Golden, CO, USA) or anti-HSP60 (BD Transduction Laboratories, Franklin Lakes, NJ, USA) to localize endoplasmic reticulum and mitochondria, respectively. The cells were incubated with TRITC-conjugated goat anti-rabbit or anti-mouse (Jackson Lab, West Grove, PA, USA) antibodies. Nuclei were visualized using TO-PRO3 (Invitrogen). The images were scanned under a $\times 40$ oil immersion objective and to avoid bleed-through effects, each dye was scanned independently by a Leica confocal microscope (laser-scanning TCS SP2) equipped with Ar/ArKr and HeNe lasers. The images were acquired and electronically merged utilizing the Leica confocal software (Leica Microsystems Heidelberg GmbH, Mannheim, Germany). Figures were processed using Adobe PhotoShop software (Adobe Systems Inc., San Jose, CA, USA).

Statistical analysis. Differences between groups were analyzed with a twosided paired or unpaired $t$-test by use of GraphPad Prism 3.00 (GraphPad Software, San Diego, CA, USA). Results were considered to be statistically significant if $P<0.05$. Experiments were replicated three times unless otherwise indicated.

\section{Conflict of Interest}

The authors declare no conflict of interest.

Acknowledgements. We are grateful to David Huang and Tristram G Parslow for providing all the bcl-2 plasmids, to Adele Petricca for secretarial assistance and to Paula Franke for English revision of the paper. We thank Stefania De Grossi and Carla Ramina for technical assistance in confocal microscopy analysis. This work was supported by grants from Italian Association for Cancer Research (DDB) and Italian Ministry of Health (DDB). CG is a PhD student of Sapienza University. YR is recipient of a fellowship from the Italian Foundation for Cancer Research.

1. Cory S, Adams JM. The Bcl2 family: regulators of the cellular life-or-death switch. Nat Rev Cancer 2002; 2: 647-656.

2. Kvansakul M, Yang H, Fairlie WD, Czabotar PE, Fischer SF, Perugini MA et al. Vaccinia virus anti-apoptotic $\mathrm{F} 1 \mathrm{~L}$ is a novel $\mathrm{Bcl}$-2-like domain-swapped dimer that binds a highly selective subset of BH3-containing death ligands. Cell Death Differ 2008; 15: 1564-1571.

3. Shibasaki F, Kondo E, Akagi T, McKeon F. Suppression of signalling through transcription factor NF-AT by interactions between calcineurin and Bcl-2. Nature 1997; 386: 728-731.

4. de Moissac D, Zheng $\mathrm{H}$, Kirshenbaum LA. Linkage of the $\mathrm{BH} 4$ domain of $\mathrm{Bcl}-2$ and the nuclear factor kappaB signaling pathway for suppression of apoptosis. J Biol Chem 1999; 274: 29505-29509.

5. Ricca A, Biroccio A, Del Bufalo D, Mackay AR, Santoni A, Cippitelli M. Bcl-2 overexpression enhances NF-kappaB activity and induces mmp-9 transcription in human MCF7(ADR) breast-cancer cells. Int J Cancer 2000; 86: 188-196.

6. Huang DC, Adams JM, Cory S. The conserved N-terminal BH4 domain of Bcl-2 homologues is essential for inhibition of apoptosis and interaction with CED-4. EMBO J 1998; 17: 1029-1039.

7. Hunter JJ, Bond BL, Parslow TG. Functional dissection of the human Bcl-2 protein: sequence requirements for inhibition of apoptosis. Mol Cell Biol 1996; 16: 877-883.

8. Trisciuoglio D, Desideri M, Ciuffreda L, Mottolese M, Ribatti D, Vacca A et al. Bcl-2 overexpression in melanoma cells increases tumor progression-associated properties and in vivo tumor growth. J Cell Physiol 2005; 205: 414-421.

9. Iervolino A, Trisciuoglio D, Ribatti D, Candiloro A, Biroccio A, Zupi G et al. Bcl-2 overexpression in human melanoma cells increases angiogenesis through VEGF mRNA stabilization and HIF-1-mediated transcriptional activity. FASEB J 2002; 16: 1453-1455.

10. Giorgini S, Trisciuoglio D, Gabellini C, Desideri M, Castellini L, Colarossi $C$ et al. Modulation of bcl-xL in tumor cells regulates angiogenesis through CXCL8 expression. Mol Cancer Res 2007; 5: 761-771.

11. Biroccio A, Candiloro A, Mottolese M, Sapora O, Albini A, Zupi G et al. Bcl-2 overexpression and hypoxia synergistically act to modulate vascular endothelial growth factor expression and in vivo angiogenesis in a breast carcinoma line. FASEB J 2000; 14: 652-660.

12. Karl E, Warner K, Zeitlin B, Kaneko T, Wurtzel L, Jin T et al. Bcl-2 acts in a proangiogenic signaling pathway through nuclear factor-kappaB and CXC chemokines. Cancer Res 2005; 65: 5063-5069.

13. Diensthuber M, Potinius M, Rodt T, Stan AC, Welkoborsky HJ, Samii M et al. Expression of bcl-2 is associated with microvessel density in olfactory neuroblastoma. $J$ Neurooncol 2008; 89: 131-139.

14. Warner KA, Miyazawa M, Cordeiro MM, Love WJ, Pinsky MS, Neiva KG et al. Endothelial cells enhance tumor cell invasion through a crosstalk mediated by CXC chemokine signaling. Neoplasia 2008; 10: 131-139. 
15. Gabellini C, Castellini L, Trisciuoglio D, Kracht M, Zupi G, Del Bufalo D. Involvement of nuclear factor-kappa $\mathrm{B}$ in bcl-xL-induced interleukin 8 expression in glioblastoma. J Neurochem 2008; 107: 871-882.

16. Fernandez A, Udagawa T, Schwesinger C, Beecken W, chilles-Gerte E, McDonnell T et al. Angiogenic potential of prostate carcinoma cells overexpressing bcl-2. J Natl Cancer Inst 2001; 93: 208-213.

17. Del Bufalo D, Trisciuoglio D, Scarsella M, Zangemeister-Wittke U, Zupi G. Treatment of melanoma cells with a bcl-2/bcl-xL antisense oligonucleotide induces antiangiogenic activity. Oncogene 2003; 22: 8441-8447.

18. Zeitlin BD, Joo E, Dong Z, Warner K, Wang G, Nikolovska-Coleska Z et al. Antiangiogenic effect of TW37, a small-molecule inhibitor of Bcl-2. Cancer Res 2006; 66: 8698-8706.

19. Anai S, Shiverick K, Medrano T, Nakamura K, Goodison S, Brown BD et al. Downregulation of BCL-2 induces downregulation of carbonic anhydrase IX, vascular endothelial growth factor, and pAkt and induces radiation sensitization. Urology 2007; 70 : 832-837.

20. Kaneko T, Zhang Z, Mantellini MG, Karl E, Zeitlin B, Verhaegen M et al. Bcl-2 orchestrates a cross-talk between endothelial and tumor cells that promotes tumor growth. Cancer Res 2007; 67: 9685-9693.

21. Trisciuoglio D, Gabellini C, Desideri M, Ziparo E, Zupi G, Del Bufalo D. Bcl-2 regulates HIF-1alpha protein stabilization in hypoxic melanoma cells via the molecular chaperone HSP90. PloS One 2010; 5: e11772.

22. Kawatani M, Imoto M. Deletion of the $\mathrm{BH} 1$ domain of $\mathrm{Bcl}-2$ accelerates apoptosis by acting in a dominant negative fashion. J Biol Chem 2003; 278: 19732-19742.

23. Lee LC, Hunter JJ, Mujeeb A, Turck C, Parslow TG. Evidence for alpha-helica conformation of an essential $\mathrm{N}$-terminal region in the human $\mathrm{Bcl} 2$ protein. J Biol Chem 1996; 271: 23284-23288

24. Shimizu S, Konishi A, Kodama T, Tsujimoto Y. BH4 domain of antiapoptotic Bcl-2 family members closes voltage-dependent anion channel and inhibits apoptotic mitochondrial changes and cell death. Proc Natl Acad Sci USA 2000; 97: 3100-3105.
25. Hotchkiss RS, McConnell KW, Bullok K, Davis CG, Chang KC, Schwulst SJ et al. TAT-BH4 and TAT-Bcl-xL peptides protect against sepsis-induced lymphocyte apoptosis in vivo. J Immunol 2006; 176: 5471-5477.

26. Hockenbery D, Nunez G, Milliman C, Schreiber RD, Korsmeyer SJ. Bcl-2 is an inner mitochondrial membrane protein that blocks programmed cell death. Nature 1990; 348: 334-336.

27. O'Connell J, Bennett MW, Nally K, O'Sullivan GC, Collins JK, Shanahan F. Interferongamma sensitizes colonic epithelial cell lines to physiological and therapeutic inducers of colonocyte apoptosis. J Cell Physiol 2000; 185: 331-338.

28. Wang Q, Gao F, May WS, Zhang Y, Flagg T, Deng X. Bcl2 negatively regulates DNA doublestrand-break repair through a nonhomologous end-joining pathway. Mol Cell 2008; 29: 488-498.

29. Denis GV, Yu Q, Ma P, Deeds L, Faller DV, Chen CY. Bcl-2, via its BH4 domain, blocks apoptotic signaling mediated by mitochondrial Ras. J Biol Chem 2003; 278: 5775-5785.

30. Wang HG, Rapp UR, Reed JC. Bcl-2 targets the protein kinase Raf-1 to mitochondria. Cell 1996; 87: 629-638

31. Jin Z, May WS, Gao F, Flagg T, Deng X. Bcl2 suppresses DNA repair by enhancing c-Myc transcriptional activity. J Biol Chem 2006; 281: 14446-14456.

32. Kang CB, Tai J, Chia J, Yoon HS. The flexible loop of Bcl-2 is required for molecular interaction with immunosuppressant FK-506 binding protein 38 (FKBP38). FEBS Lett 2005; 579: 1469-1476.

33. Barth S, Nesper J, Hasgall PA, Wirthner R, Nytko KJ, Edlich F et al. The peptidyl prolyl cis/ trans isomerase FKBP38 determines hypoxia-inducible transcription factor prolyl-4hydroxylase PHD2 protein stability. Mol Cell Biol 2007; 27: 3758-3768.

34. Kim BY, Kim H, Cho EJ, Youn HD. Nur77 upregulates HIF-alpha by inhibiting pVHLmediated degradation. Exp Mol Med 2008; 40: 71-83.

35. Liu YV, Baek JH, Zhang H, Diez R, Cole RN, Semenza GL. RACK1 competes with HSP90 for binding to HIF-1alpha and is required for O(2)-independent and HSP9O inhibitorinduced degradation of HIF-1alpha. Mol Cell 2007; 25: 207-217.

36. Trisciuoglio D, lervolino A, Zupi G, Del Bufalo D. Involvement of PI $3 K$ and MAPK signaling in bcl-2-induced vascular endothelial growth factor expression in melanoma cells. Mol Biol Cell 2005; 16: 4153-4162.

Supplementary Information accompanies the paper on Cell Death and Differentiation website (http://www.nature.com/cdd) 